\title{
Factors Affecting Final Surgical Outcome of Combined Trabeculotomy-Trabeculectomy in Primary Congenital Glaucoma
}

\author{
Marwa A Khairy (D) \\ Said Kenawy \\ Khaled Mohamed Fawzi \\ Haitham Y Al-Nashar \\ Ophthalmology Department, Faculty of \\ Medicine, Zagazig University, Zagazig, \\ Egypt
}

\begin{abstract}
Purpose: To evaluate different pre-operative variables on the success of combined trabeculotomy-trabeculectomy (CTT) surgery in patients with primary congenital glaucoma (PCG) to predict those at higher risk for surgical failure and for proper parent counseling.

Patients and Methods: Sixty-three eyes of patients with PCG were treated either with CTT without augmentation, or CTT augmented with mitomycin-C $(0.2 \mathrm{mg} / \mathrm{mL})$ in both subconjunctival space and under scleral flap for 3 minutes, or with CTT augmented with a collagen implant under both the scleral flap and the conjunctiva. Cases showed surgical failure was reported and evaluated in relation to different pre-operative variables.

Results: Complete success (IOP $\leq 21 \mathrm{mmHg}$ ) was achieved in 52 cases $(82.5 \%$ ). Cumulative success probability was calculated using Kaplan-Meier survival analysis, proving that higher pre-operative intraocular pressure (IOP) was associated with higher failure rates $(28.6 \%$ for pre-operative IOP $\geq 30 \mathrm{mmHg}$ versus $4.8 \%$ for $\mathrm{IOP}<30 \mathrm{mmHg}$ ), with $\mathrm{P}$ value $=0.007$.

Conclusion: CTT is an effective surgical intervention in PCG patients without sight threatening complications. Univariate survival analysis showed higher rates of surgical failure in patients with higher pre-operative IOP, while other pre-operative variables were irrelevant.
\end{abstract}

Keywords: buphthalmos, Kaplan-Meier survival analysis, surgical failure

\section{Introduction}

Congenital glaucoma is a major cause of childhood blindness worldwide, with variable birth prevalence in different populations worldwide, ${ }^{1}$ and is responsible for $10.8 \%$ of all visual impairments in children. ${ }^{2}$

The disease is usually managed surgically, with medical treatment playing a temporary or an adjunctive role. Multiple surgical modalities have been described, however surgery in a buphthalmic eye with disturbed anatomy is challenging and is associated with higher failure rates and multiple complications than in adults. Early and proper surgical intervention can achieve a favorable outcome and preserve patients' vision. ${ }^{1,3}$

A milder form of the disease associated with only trabeculodysgenesis can respond well to trabeculotomy surgery, however, the more advanced form with iridotrabeculodysgenesis, and corneotrabeculodysgenesis showed less favorable results to trabeculotomy. ${ }^{4,5}$ Combining trabeculotomy with trabeculectomy is one of the preferred surgical options, which showed favorable results in congenital glaucoma, and is advised mainly for treating moderate to severe forms of the disease, as the procedure
Correspondence: Marwa A Khairy Ophthalmology Department, Faculty of Medicine, Zagazig University, Zagazig, Egypt

Tel +20-I I I I80I956

Fax+20-552353738

Emailma_kh87@yahoo.com 
provides dual pathways for aqueous drainage. ${ }^{6}$ The procedure is also recommended for severe familial form of the disease which occur mainly in Indian and Middle East populations which showed less favorable results to goniotomy compared to the Western population, another advantage is that in cases where Schlemm's canal cannot be identified and cannulated because of the disturbed limbal anatomy in larger eyes, the added trabeculectomy fistula can still function and lower the rates of failure. ${ }^{6-8}$

\section{Patients and Methods}

The study was carried out in accordance with the principles of the Declaration of Helsinki, and approval from the Ethical Committee of Zagazig Faculty of Medicine and an Institutional Review Board (IRB) code was obtained (IRB No: ZU-IRB \#5362/10-4-2019). Informed consent was obtained from the parents of all patients.

This clinical trial included 63 eyes of 36 patients with primary congenital glaucoma (PCG), eyes were randomized by random allocation computer program into 3 equal groups (21 eyes in each group); eyes in group I were treated with combined trabeculotomy-trabeculectomy (CTT), group II were treated with CTT augmented with mitomycin-C, while eyes in group III were treated with CTT augmented with collagen implant (Ologen).

\section{Inclusion Criteria}

Patients younger than 3 years diagnosed as having PCG were included.

\section{Exclusion Criteria}

Patients with previous ocular surgery, secondary glaucoma, or other ocular pathologies were excluded from the study. Also, those lost during the follow-up visits (lost for more than two visits during follow-up) were withdrawn from the study.

\section{Pre-operative Assessment}

Pre-operative patients' evaluation including demographic data (age, sex, consanguinity and family history). Also, examination under general anesthesia (EUGA) for intraocular pressure (IOP) calculation using Perkins applanation tonometer, horizontal corneal diameters using surgical caliber, anterior segment examination using surgical microscope for the degree of corneal edema and to exclude other pathologies, fundus examination to assess for cupping and exclude retinal pathology by indirect ophthalmoscope if corneal clarity allows for fundus visualization.

\section{Surgical Techniques}

Eyes in group I; were treated with CTT.

Eyes in group II; were treated with CTT augmented with mitomycin-C $(0.2 \mathrm{mg} / \mathrm{mL})$ in both subconjunctival space and under scleral flap for 3 minutes.

Eyes in group III; were treated with CTT augmented with a collagen implant (Ologen TM, Aeon Astron Europe B.V, Leiden, The Netherlands) divided unequally, with the smaller part implanted under the scleral flap and the larger part under the conjunctiva.

\section{Post-Operative Treatment}

All patients received topical antibiotic eye drops for two weeks and topical prednisolone acetate $1 \%$ eye drops five times per day for a week, with gradual withdrawal over another two weeks, also cyclopentolate drops twice daily for a week.

\section{Post-Operative Follow Up}

All patients were seen at the first day looking for shallow or lost anterior chamber, red reflex, IOP and any sign of ocular inflammation. Patients were seen again at one, and two weeks and at first, second, third, sixth, ninth and twelfth months post-operative.

\section{Success Criteria}

Complete success was defined as an IOP $\leq 21 \mathrm{mmHg}$ without added antiglaucoma medications or needing another glaucoma surgery and without sight threatening complications. Qualified success was considered when the above criteria were achieved, but with added antiglaucoma medication. Failure was defined as IOP being $>21 \mathrm{mmHg}$ with maximum topical antiglaucoma medications, the requirement of another surgical intervention to lower IOP, or the appearance of sight threatening complications.

\section{Statistical Analysis}

All statistical analyses were performed using Statistical Package for the Social Sciences (SPSS, version 25.0). According to the type of data qualitative representation is as number and percentage, quantitative continuous group is represented by mean with standard deviation [SD]. The effect of individual clinical and demographic pre-operative variables on the final surgical outcome of treatment was analyzed using Kaplan-Meier survival analysis. P value $<0.05$ was considered significant. 


\section{Results}

63 eyes of 36 patients with PCG were included in this study. 27 patients had bilateral disease, while 9 had a unilaterally affected eye. A random allocation computer program was used to assign each eye to one of the study groups. The included patients were 24 (66.7\%) males, and 12 (33.3\%) females. The mean age at time of surgery was $6.18 \pm 2.8$ months (Range 1.5-11 months). Positive family history of PCG was recorded in 9 patients $(25 \%)$, while the remaining patients, 27 (75\%), denied having any family member with PCG. Regarding consanguinity, 13 (36.1\%) patients had positive consanguinity between both parents, while 23 (63.9\%) eyes were negative. (Table 1).

Pre-operative examination data were as follows: mean pre-operative IOP was $27.65 \pm 2.6 \mathrm{mmHg}$, with a range of (23-34 mmHg). Mean pre-operative corneal diameter was 13 $\pm 0.56 \mathrm{~mm}$ (range 12-14 mm). Pre-operative corneal edema was recorded in all eyes, with 22 (34.9\%) eyes, with superficial epithelial edema, and 32 (50.8\%) showed central edema involving both epithelium and parenchyma, while 9 (14.3\%) had total diffuse edema obscuring fundus details (Table 1).

Table I Pre-operative Patient's Data

\begin{tabular}{|c|c|}
\hline Variable & (Mean \pm SD)/No (\%) \\
\hline $\begin{array}{l}\text { Sex } \\
\text {-Male patients } \\
\text {-Female patients }\end{array}$ & $\begin{array}{l}\text { - } 24(66.7 \%) \\
\text { - } 12(33.3 \%)\end{array}$ \\
\hline Patients' Age & $\begin{array}{c}6.18 \pm 2.8 \text { months } \\
\text { Range (I.5-II months) }\end{array}$ \\
\hline $\begin{array}{l}\text { Family history } \\
\text {-Positive patients } \\
\text {-Negative patients }\end{array}$ & $\begin{array}{l}\text { - } 9(25 \%) \\
\text { - } 27(75 \%)\end{array}$ \\
\hline $\begin{array}{l}\text { Consanguinity } \\
\text {-Positive patients } \\
\text {-Negative patients }\end{array}$ & $\begin{array}{l}\text { - } 13(36.1 \%) \\
\text { - } 23(63.9 \%)\end{array}$ \\
\hline IOP & $\begin{array}{c}27.65 \pm 2.6 \mathrm{mmHg} \\
\text { Range }(23-34 \mathrm{mmHg})\end{array}$ \\
\hline Corneal diameter & $\begin{array}{c}13 \pm 0.56 \mathrm{~mm} \text { Range } \\
\quad(12-14 \mathrm{~mm})\end{array}$ \\
\hline $\begin{array}{l}\text { Corneal edema } \\
\text {-Superficial epithelial edema } \\
\text {-Central edema involving both epithelium } \\
\text { and parenchyma } \\
\text {-Total diffuse edema obscuring fundus } \\
\text { details }\end{array}$ & $\begin{array}{l}\text { - } 22(34.9 \%) \\
\text { - } 32(50.8 \%) \\
\text { - } 9(14.3 \%)\end{array}$ \\
\hline
\end{tabular}

Total success (complete and qualified) was achieved in 55 cases $(87.3 \%)$ and failure was reported in 8 cases (12.7\%). Complete success was achieved in 52 cases (82.5\%). Cumulative success probability was determined using Kaplan-Meier survival analysis, with univariate comparisons of final surgical outcome according to patient pre-operative characteristics (Table 2).

Comparing the type of surgical intervention to failure, 3 cases (14.3\%) showed failure in group I, and 2 cases $(9.5 \%)$ in group II, while group III had 3 failed cases (14.3\%), with $\mathrm{P}$ value 0.882 , which was statistically insignificant.

Comparing age at time of surgical intervention to failure, number of eyes below 6 months of age were 26 $(41.3 \%)$, with 4 of them (15.4\%) showing failure, while there were 37 eyes $\geq 6$ months $(58.7 \%)$, with 4 of them $(10.8 \%)$ showing failure. $\mathrm{P}$ value $=0.553$, which was statistically insignificant.

Regarding the patient's sex, 42 eyes (66.7\%) were male, with 7 (16.7\%) experiencing failure, while 21 eyes $(33.3 \%)$ were female, with $1(4.8 \%)$ failed eye. $\mathrm{P}$ value $=$ 0.180 , which was statistically insignificant.

Comparing family history to failure cases, 15 eyes (23.8\%) had a positive family history of PCG. 2 (13.3\%) of them experienced failure. While 48 eyes $(76.2 \%)$ had a negative family history, $6(12.5 \%)$ of them experienced failure. $\mathrm{P}$ value $=0.906$ which was statistically insignificant.

Regarding consanguinity, 22 eyes (34.9\%) had positive consanguinity, 4 (18.2\%) of them showed failure. 41 eyes (65.1\%) had negative consanguinity, with $4(9.8 \%)$ of them failing.

Comparing pre-operative IOP to failure, 42 eyes (66.7\%) had an IOP of less than $30 \mathrm{mmHg}$, of them 2 eyes $(4.8 \%)$ showed failure. While 21 eyes $(33.3 \%)$ had a pre-operative IOP $\geq 30 \mathrm{mmHg}$, with 6 eyes $(28.6 \%)$ failing among them. $\mathrm{P}$ value $=0.007$, which was statistically significant (Figure 1).

Regarding pre-operative corneal diameter, 25 eyes $(39.7 \%)$ had a diameter of less than $13 \mathrm{~mm}$, of them 3 eyes (12\%) showed failure. While 38 eyes $(60.3 \%)$ had a diameter $\geq 13 \mathrm{~mm}$, with $5(13.2 \%)$ of them showing failure. $\mathrm{P}$ value $=0.897$, which was statistically insignificant.

Comparing pre-operative corneal clarity to failure showed 22 eyes (34.9\%) with superficial epithelial edema, $4(18.2 \%)$ of them showed failure. A central edema involving both epithelium and parenchyma was 
Table 2 Probability Outcome of CTT Surgery in PCG Using Kaplan-Meier Survival Analysis, with Univariate Analysis Comparing Final Surgical Outcome According to Pre-Operative Variables

\begin{tabular}{|c|c|c|c|c|c|c|}
\hline $\begin{array}{l}\text { Total Number of Eyes According } \\
\text { to Pre-Operative Variable (\%) }\end{array}$ & $\begin{array}{l}\text { Number } \\
\text { of } \\
\text { Failures }\end{array}$ & $\begin{array}{l}\text { Probability } \\
\text { of Failure }\end{array}$ & $\begin{array}{l}\text { Probability of } \\
\text { Success at } 95 \% \\
\text { Cl }\end{array}$ & $\begin{array}{l}\text { Log } \\
\text { Rank } \\
\text { Test }\end{array}$ & $\begin{array}{l}\text { Mean Survival Time } \\
\text { (Days) }\end{array}$ & $P$ value \\
\hline $\begin{array}{l}\text { Between groups } \\
- \text { CTT = } 21 \quad(33.3 \%) \\
- \text { CTTM = } 21 \quad(33.3 \%) \\
- \text { CTTO = } 21 \quad(33.3 \%)\end{array}$ & $\begin{array}{l}\bullet \\
\bullet \\
\bullet \\
\bullet\end{array}$ & $\begin{array}{l}\bullet 0.143 \\
-0.095 \\
\bullet 0.143\end{array}$ & 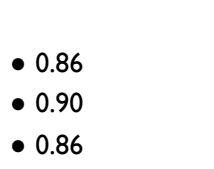 & 0.252 & $\begin{array}{l}\text { - } 318.6(269.9-367.3) \\
\text { - } 333(291.04-375.2) \\
\text { - } 320(272.8-367.2)\end{array}$ & 0.882 \\
\hline $\begin{array}{l}\text { Age at surgery } \\
-<6 \text { months }=26(41.3 \%) \\
-\geq 6 \text { months }=37(58.7 \%)\end{array}$ & $\begin{array}{l}-4 \\
-4\end{array}$ & $\begin{array}{l}\bullet 0.154 \\
\bullet 0.108\end{array}$ & $\begin{array}{l}\bullet 0.85 \\
\bullet 0.89\end{array}$ & 0.351 & $\begin{array}{l}\text { - } 313.46(267-359.9) \\
\text { - } 331.22(299.9-362.5)\end{array}$ & 0.553 \\
\hline $\begin{array}{l}\text { Sex } \\
- \text { Male = } 42(66.7 \%) \\
- \text { Female }=21 \quad(33.3 \%)\end{array}$ & $\begin{array}{l}\bullet 7 \\
\bullet \quad 1\end{array}$ & $\begin{array}{l}\bullet \\
\bullet\end{array} .167$ & $\begin{array}{l}\bullet 0.83 \\
\bullet 0.95\end{array}$ & 1.8 & $\begin{array}{l}\text { - } 310.6(273.8-347.4) \\
\text { - } 350.5(322.7-378.3)\end{array}$ & 0.180 \\
\hline $\begin{array}{l}\text { Family history } \\
\text {-Positive = I5 (23.8\%) } \\
\text {-Negative = } 48(76.2 \%)\end{array}$ & $\begin{array}{l}\text { - } 2 \\
\text { - } 6\end{array}$ & $\begin{array}{l}\bullet \\
\bullet\end{array} .133$ & $\begin{array}{l}\bullet 0.87 \\
\bullet 0.88\end{array}$ & 0.014 & $\begin{array}{l}\text { - } 320.3(262.7-377.9) \\
\text { - } 325(295-354.9)\end{array}$ & 0.906 \\
\hline $\begin{array}{l}\text { Consanguinity } \\
\text {-Positive = } 22(34.9 \%) \\
\text {-Negative = } 41 \text { (65.1\%) }\end{array}$ & $\begin{array}{l}-4 \\
\text { - } 4\end{array}$ & $\begin{array}{l}\bullet \\
\bullet\end{array} .182$ & $\begin{array}{l}\bullet 0.82 \\
\bullet 0.90\end{array}$ & 0.95 & $\begin{array}{l}\text { - } 305.5(252.6-358.3) \\
\text { - } 333.8(304.7-362.9)\end{array}$ & 0.330 \\
\hline $\begin{array}{l}\text { IOP } \\
-<30 \mathrm{mmHg}=42(66.7 \%) \\
-\geq 30 \mathrm{mmHg}=21(33.3)\end{array}$ & $\begin{array}{l}\text { - } 2 \\
\text { - } 6\end{array}$ & $\begin{array}{l}\bullet \\
\bullet\end{array} .048$ & $\begin{array}{l}\bullet 0.95 \\
\bullet 0.71\end{array}$ & 7.28 & $\begin{array}{l}\text { - } 349.8(329.1-370.1) \\
\text { - } 272.1(209.3-335)\end{array}$ & 0.007 \\
\hline $\begin{array}{l}\text { Corneal diameter } \\
-<13 \mathrm{~mm}=25(39.7 \%) \\
-\geq 13 \mathrm{~mm}=38(60.3 \%)\end{array}$ & $\begin{array}{l}\text { - } 3 \\
\text { - } 5\end{array}$ & $\begin{array}{l}-0.12 \\
\bullet 0.13\end{array}$ & $\begin{array}{l}\bullet 0.88 \\
\bullet 0.87\end{array}$ & 0.017 & $\begin{array}{l}\text { - } 326(284.6-367.4) \\
\text { - } 322.5(287.7-357.3)\end{array}$ & 0.897 \\
\hline $\begin{array}{l}\text { Corneal clarity } \\
-\mathrm{SE}=22(34.9 \%) \\
-\mathrm{CE}=32(50.8 \%) \\
-\mathrm{TE}=9(14.3 \%)\end{array}$ & 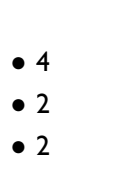 & $\begin{array}{l}-0.182 \\
-0.063 \\
-0.22\end{array}$ & 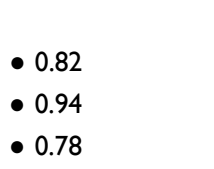 & 2.68 & $\begin{array}{l}\text { - } 305.5(252.6-358.3) \\
\text { - } 345.9(320.4-371.5) \\
\text { - } 290.6(199.6-381.5)\end{array}$ & 0.262 \\
\hline
\end{tabular}

Abbreviations: $\mathrm{Cl}$, confidence interval; IOP, intraocular pressure; CTT, combined trabeculotomy-trabeculectomy; CTTM, combined trabeculotomy-trabeculectomy augmented with mitomycin-C; CTTO, combined trabeculotomy-trabeculectomy augmented with Ologen; SE, superficial epithelial edema; CE, central edema involving both epithelium and parenchyma; TE, total diffuse edema obscuring fundus details.

reported in 32 eyes $(50.8 \%)$, with $2(6.3 \%)$ of them experiencing failure. Total diffuse edema obscuring fundus details was reported in 9 eyes (14.3\%), 2 (22.2\%) of them experienced failure. $\mathrm{P}$ value $=0.262$, which was statistically insignificant.

No sight threatening complications were recorded in any group, like endophthalmitis or retinal detachment. Only a few cases showed intraoperative hyphema that needed an anterior chamber wash. Also post-operative hypotony was recorded in the first and second group and was managed conservatively.

Cases with failed primary surgery needed another surgical intervention in the form of CTT augmented with
MMC. 5 eyes were controlled by the second procedure, while the other 3 had uncontrolled IOP and were scheduled for valve surgery.

\section{Discussion}

The definitive treatment of PCG is surgical, with wide varieties of surgical approaches, however, CTT showed promising results with higher success rates and better IOP control for a single procedure. ${ }^{8}$ One of the advantages of CTT is that it can be performed in eyes with significant ocular enlargement and large corneal diameter which was considered as a challenge to goniotomy surgery. ${ }^{7,9}$ 


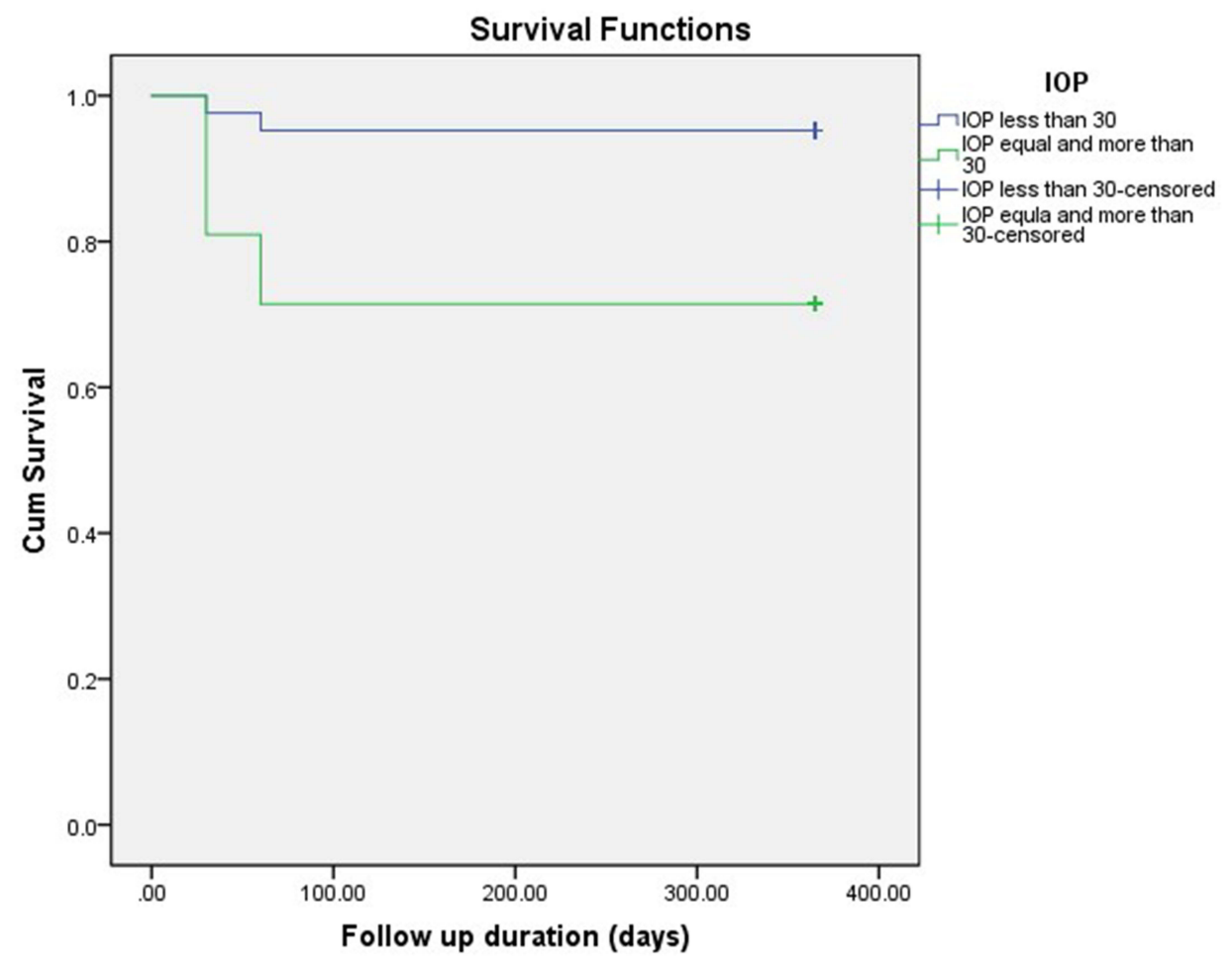

Figure I Kaplan-Meier curve showing the success probabilities in relation to pre-operative IOP.

The higher success rates of CTT were explained by the supplementary outflow pathway that the procedure creates, with less risk of surgical failure in cases where trabeculotomy was not done properly or Schlemm's canal cannot be identified. ${ }^{6,710}$ The addition of antimetabolites to augment CTT surgery is a matter of great debate among surgeons, ${ }^{7,11,12}$ it's believed by some surgeons to increase success rates as well as increase the rate of complications. ${ }^{6,12}$ In our study we reported a complete success in 52 cases $(82.5 \%)$, with total success in 55 cases $(87.3 \%)$ and failure in only 8 cases $(12.7 \%)$. In univariate analysis to evaluate the role of different preoperative risk factors on treatment outcome in the present study, we evaluated the type of surgery, either CTT alone or CTT augmented with the addition of MMC or with added Ologen implant on failure. P value was 0.882 , which indicates that the three surgical modalities were equally effective.

Mandal et al reported a success probability of $85.2 \%$ at first year after CTT surgery (complete success at IOP $<16$ $\mathrm{mmHg}$ under general anesthesia or $<21 \mathrm{mmHg}$ in older patients examined by slit lamp, without cupping progression or increase in corneal diameter), ${ }^{8}$ Mullaney et al reported $78 \%$ success rates (IOP, $<21 \mathrm{mmHg}$ ) in congenital glaucoma patients without coexistent anterior segment anomalies after CTT surgery. ${ }^{11}$ Also, Essuman et al reported a $79 \%$ overall surgical success rate of CTT. ${ }^{13}$ Our results are comparable to the previously mentioned studies, with equal efficacy in either augmented or nonaugmented procedure.

Other pre-operative risk factors including age at time of surgical intervention, patient's sex, family history of PCG, consanguinity, pre-operative corneal diameter or corneal clarity were all irrelevant compared to surgical failure. The only factor significantly associated with higher failure rates was pre-operative IOP, as cases with pre-operative IOP $\geq 30 \mathrm{mmHg}$ were associated with higher failure rates $(28.6 \%)$, compared to cases with IOP $<30 \mathrm{mmHg}(4.8 \%)$, with a $\mathrm{P}$ value equal to 0.007 , which was statistically significant (Table 2). Our results were consistent with Mandal et al who found a strong correlation between preoperative IOP and failure, with a higher risk of surgical failure among patients with higher pre-operative IOP values. Patients with pre-operative IOP $>35 \mathrm{mmHg}$ had $31.9 \%$ failure rates, while those with an IOP $\leq 35$ $\mathrm{mmHg}$ showed only a $15.1 \%$ failure rate, with $\mathrm{P}$ value $=0.003{ }^{8}$ 
Mandal et al also, found other factors associated with failure in univariate analysis, which included patient's age at time of surgery, and a history of previous glaucoma surgery. He stated that patients older than 6 months of age at the time of surgery had higher failure rates (21.4\%) compared to those $\leq 6$ months (12.8\%), with $\mathrm{P}$ value $=0.010$. However, the author stated that the data regarding the age of disease onset was missing in $61.4 \%$ of cases, that's why he did not comment on that factor. ${ }^{8}$ In our study we reported higher failure rates in patients operated below 6 months of age (15.4\%) compared to those operated at or older than 6 months (10.8\%), however there was no statistically significant difference $(\mathrm{P}$ value $=0.553)$. This matches other studies which reported that the earlier onset of the disease is associated with a more severe form and worse surgical prognosis. ${ }^{14,15}$

Another variable Mandal et al investigated was prior glaucoma surgery. The author found that prior surgical intervention was associated with higher failure rates of the second procedure (43.3\%), compared to primary surgery $\left(14.8 \%\right.$ ), with $\mathrm{P}$ value $<0.0001{ }^{8}$ However, in our study we operated upon primary cases only, and excluded those with previous surgical intervention.

Limitations of our study are the small number of the patients included and the short follow up period.

\section{Conclusion}

In conclusion, the study showed that the only factor which was statistically significant regarding surgical failure in univariate survival analysis was pre-operative IOP, other factors did not show statistically significant differences.

\section{Abbreviations}

CTT, combined trabeculotomy-trabeculectomy surgery; PCG, primary congenital glaucoma; EUGA, examination under general anesthesia; IRB, institutional review board; IOP, intraocular pressure.

\section{Acknowledgments}

The authors would like to express their deep gratitude to the patients who participated in this study.

\section{Disclosure}

The authors report no conflicts of interest in this work.

\section{References}

1. Badawi AH, Al-Muhaylib AA, Al Owaifeer AM, Al-Essa RS, AlShahwan SA. Primary congenital glaucoma: an updated review. Saudi J Ophthalmol. 2019;33:382-388. doi:10.1016/j.sjopt.20 19.10.002

2. Haddad MA, Sei M, Sampaio MW, Kara-José N. Causes of visual impairment in children: a study of 3210 cases. J Pediatr Ophthalmol Strabismus. 2007;44:232-240. doi:10.3928/01913913-20070701-04

3. Papadopoulos M, Edmunds B, Fenerty C, Khaw PT. Childhood glaucoma surgery in the 21st century. Eye (Lond). 2014;28:931-943. doi:10.1038/eye.2014.140

4. Hoskins HD Jr, Shaffer RN, Hetherington J. Anatomical classification of the developmental glaucomas. Arch Ophthalmol. 1984;102 (9):1331-1336. doi:10.1001/archopht.1984.01040031081030

5. Luntz MH. The choice of surgical procedure in congenital, infantile, and juvenile glaucoma. J Ophthalmic Nurs Technol. 1990;9 (3):100-101.

6. Al-Hazmi A, Awad A, Zwaan J, Al-Mesfer SA, Al-Jadaan I, AlMohammed A. Correlation between surgical success rate and severity of congenital glaucoma. $\mathrm{Br} J$ Ophthalmol. 2005;89:449-453. doi:10.1136/bjo.2004.047761

7. Mandal A, Matalia J, Nutheti R, et al. Combined trabeculotomy and trabeculectomy in advanced primary developmental glaucoma with corneal diameter of $14 \mathrm{~mm}$ or more. Eye. 2006;20:135-143. doi:10.1038/sj.eye.6701817

8. Mandal AK, Gothwal VK, Nutheti R. Surgical outcome of primary developmental glaucoma: a single surgeon's long-term experience from a tertiary eye care centre in India. Eye (Lond). 2007;21:764-774. doi:10.1038/sj.eye.6702324

9. Helmy H. Ab interno goniotomy combined with Ab externo trabeculotomy in advanced primary congenital glaucoma patients: 2-year follow-up. Clin Ophthalmol. 2021;15:565-574. doi:10.2147/OPTH. S292168

10. Sood D, Rathore A, Sood I, et al. Long-term outcome of combined trabeculotomy-trabeculectomy by a single surgeon in patients with primary congenital glaucoma. Eye. 2018;32:426-432. doi:10.1038/ eye.2017.207

11. Mullaney PB, Selleck C, Al-Awad A, Al-Mesfer S, Zwaan J. Combined trabeculotomy and trabeculectomy as an initial procedure in uncomplicated congenital glaucoma. Arch Ophthalmol. 1999;117 (4):457-460. doi:10.1001/archopht.117.4.457

12. Al-Hazmi A, Zwaan J, Awad A, al-Mesfer S, Mullaney PB, Wheeler DT. Effectiveness and complications of mitomycin C use during pediatric glaucoma surgery. Ophthalmology. 1998;105 (10):1915-1920. doi:10.1016/S0161-6420(98)91041-7

13. Essuman VA, Braimah IZ, Ndanu TA, Ntim-Amponsah CT. Combined trabeculotomy and trabeculectomy: outcome for primary congenital glaucoma in a West African population. Eye (Lond). 2011;25:77-83. doi:10.1038/eye.2010.156

14. Khaw PT. What is the best primary surgical treatment for the infantile glaucomas? Br J Ophthalmol. 1996;80(6):495-496. doi:10.1136/ bjo.80.6.495

15. Dureau P, Dollfus H, Cassegrain C, Dufier JL. Long-term results of trabeculectomy for congenital glaucoma. J Pediatr Ophthalmol Strabismus. 1998;35(4):198-202. doi:10.3928/0191-3913-19980 701-05 


\section{Publish your work in this journal}

Clinical Ophthalmology is an international, peer-reviewed journal covering all subspecialties within ophthalmology. Key topics include: Optometry; Visual science; Pharmacology and drug therapy in eye diseases; Basic Sciences; Primary and Secondary eye care; Patient Safety and Quality of Care Improvements. This journal is indexed on PubMed

Submit your manuscript here: https://www.dovepress.com/clinical-ophthalmology-journal
Central and CAS, and is the official journal of The Society of Clinical Ophthalmology (SCO). The manuscript management system is completely online and includes a very quick and fair peer-review system, which is all easy to use. Visit http://www.dovepress.com/ testimonials.php to read real quotes from published authors. 